\title{
Estandarización de la técnica de PCR para amplificar el genoma mitocondrial de las tortugas cabezona (Caretta caretta) y carey (Eretmochelys imbricata) anidantes del Caribe colombiano
}

\author{
Gerson Beltrán-Torres, Katherin Otálora, Ledy Angélica Daza, Javier Hernández-Fernández*
}

Universidad Jorge Tadeo Lozano, Facultad de Ciencias e Ingeniería. Grupo de Investigación Genética, Biología Molecular y Bioinformática - GENBIMOL, Carrera 4 № 22-61Bogotá D.C., Colombia. * Autor para correspondencia: javier.hernandez@utadeo.edu.co

PCR Standardization to amplify the mitochondrial genome of nesting loggerhead turtles (Caretta caretta) and hawksbill (Eretmochelys imbricata) in the Colombian Caribbean

\begin{abstract}
The hawksbill turtle, Eretmochelys imbricata, and loggerhead, Caretta caretta, are distributed in tropical waters of the Indo- Pacific and Atlantic, this species are considered important into ecosystems. Both turtles are listed as critically endangered since they have been exploited by their shell, eggs and meat. Population of both species are found in a significant population decline in the Colombian Caribbean. Genetic studies of mitochondrial DNA allow the support of management and conservation plans. In the present study the best conditions for the PCR have been standardized for the amplification of 22 fragments of $800 \mathrm{bp}$ overlapping in $50 \mathrm{bp}$ of hawksbill and loggerhead turtles mitogenoma. Primers-oligonucleotides were designed for amplification of these mitogenomas from previously described sequences of the Chelonia mydas green turtle. The concentration of $\mathrm{Mg}^{+2}$, DNA, primers-oligonucleotides and the annealing temperature were evaluated. The standard PCR reaction was obtained in a final volume of $25 \mu$ containing 20-70 ng of DNA, 0,5-1 mM each primers-oligonucleotide, 1.5-3.0 mM Mg${ }^{+2}, 1 \mathrm{U}$ of Taq polymerase and 0.2 mM of dNTP's. Optimized amplification parameters were: initial denaturation of $5 \mathrm{~min}$ at $94^{\circ} \mathrm{C}$, followed by 35 cycles of $94^{\circ} \mathrm{C}$ for $1 \mathrm{~min}, 37-50^{\circ} \mathrm{C}$ for 1 min (according to the primer-oligonucleotide) and $72{ }^{\circ} \mathrm{C}$ for $1 \mathrm{~min} .63 \%$ of the sequence of the hawksbill turtle and $68 \%$ of the loggerhead turtle were obtained. These sequences had 99-100 \% identity with the sequences previously reported.
\end{abstract}

Keywords: Mitochondrial DNA, PCR, Caretta caretta, Eretmochelys imbricata.

Editor: Pataquiva A.

Citation: Beltrán-Torres G, Otálora K, Ledy Angélica Daza Hernández-Fernández J. (2013) PCR Standardization to amplify the mitochondrial genome of nesting loggerhead turtles (Caretta caretta) and hawksbill (Eretmochelys imbricata) in the Colombian Caribbean. Revista Mutis. vol. 3 (2) pag. 21-30

Received: June 1, 2013; Accepted: September 29, 2013; Published on line: December 15, 2013

Copyright: $\odot 2013$ Beltrán-Torres et al. This is an open-access article, which permits unrestricted use, distribution and reproduction in any medium, provided the original author and source are credited

\section{Resumen}

Las tortugas marinas, Eretmochelys imbricata y Caretta caretta se encuentran distribuidas en aguas tropicales del Indo-Pacífico y Atlántico y son consideradas especies importantes dentro del ecosistema. Estas tortugas se han catalogado en peligro crítico ya que han sido explotadas por su caparazón, huevos y carne. Las poblaciones de ambas especies se encuentran 
en un declive poblacional significativo en el Caribe colombiano. Los estudios genéticos del ADN mitocondrial permiten el apoyo de planes de manejo y conservación. En el presente estudio se estandarizaron las mejores condiciones de la técnica de PCR para la amplificación de 22 fragmentos de 800 pb solapadas en $50 \mathrm{pb}$ del mitogenoma de las tortugas E. imbricata y C. caretta. Se diseñaron oligonucleótidos-primers para la amplificación de estos mitogenomas a partir de secuencias previamente descritas de la tortuga verde Chelonia mydas. Se evaluó la concentración de $\mathrm{Mg}^{+2}, \mathrm{ADN}$, oligonucleótidos-primers y la temperatura de anillamiento. La reacción estandarizada de PCR se obtuvo en un volumen final de $25 \mu$, conteniendo 20-70 ng de DNA, 0,5-1 mM de cada oligonucleótidos-primers, 1,5-3,0 mM de $\mathrm{Mg}^{+2}, 1 \mathrm{U}$ de Taq polimerasa y 0,2 mM de cada dNTP's. Los parámetros de amplificación optimizados fueron: desnaturalización inicial de 5 min a $94{ }^{\circ} \mathrm{C}$, seguida por 35 ciclos de $94^{\circ} \mathrm{C}$ por $1 \mathrm{~min}, 37-50^{\circ} \mathrm{C}$ por $1 \mathrm{~min}$ (de acuerdo a los oligonucleótidos-primers) y $72{ }^{\circ} \mathrm{C}$ por $1 \mathrm{~min}$. Se obtuvo el $63 \%$ de la secuencia de la tortuga carey y el $68 \%$ de la tortuga cabezona. Estas secuencias presentaron un 99-100 \% de identidad con las secuencias previamente reportadas.

Palabras clave: ADN mitocondrial, PCR, Caretta caretta, Eretmochelys imbricata.

\section{Introducción}

La tortuga carey, Eretmochelys imbricata (Linnaeus, 1766) y la tortuga cabezona Caretta caretta (Linnaeus, 1758) pertenecientes a la familia Cheloniidae, son especies consideradas componente relevante de diferentes hábitats vitales para el ecosistema (arrecifes de coral, praderas de pastos marinos, fondos blandos, etc.) (Eckert et al., 2000); reportadas en latitudes templadas tropicales y subtropicales, estas tortugas anidan en los mares del Caribe colombiano, pero a pesar de su amplia distribución E. imbricata esta reportada por la UICN en la categoría A2bd de "en peligro crítico" (Meylan \& Donnelly, 1999, y C. caretta "en peligro" A1 abd de extinción (IUCN, 2013). Estas tortugas están protegidas por leyes nacionales y acuerdos internacionales que pretenden mitigar la disminución de hembras anidantes por causas de origen antrópico (Barreto, 2011, SWOT, 2012, IUCN, 2013). Las poblaciones de estas tortugas evidencian una problemática en los niveles de abundancia debido a sus estrategias de reproducción $\mathrm{K}$, debido a que tardan entre 20 y 30 años en alcanzar la madurez sexual (Machado y Bermejo, 2012) y producen muy pocos descendientes. El declive de las poblaciones de estas tortugas en el Caribe colombiano es un fenómeno recurrente (Amorocho, 1999, Invemar, 2003, Barreto, 2011). Ese declive poblacional se está produciendo debido a factores como: comercialización de la carne y los caparazones y el consumo de los huevos y aceite (Rueda, 2001, SWOT, 2012). A esto se suma la captura incidental por pesquerías industriales y artesanales, la pérdida del hábitat (Eckert, 2000, Barreto, 2011) y la polución marina (Barreto, 2011, SWOT, 2012). El Ministerio de Ambiente y la Dirección Nacional de Ecosistemas en Colombia han evaluado a estas tortugas como especies problema debido al bajo número de hembras anidantes en el mar Caribe, problemática que genera gran interés para adelantar investigaciones en áreas como la filogenética, filogeografía, conservación genética, evolución y la genética de poblaciones.

El uso de herramientas moleculares como el ADN mitocondrial (ADNmt) han alcanzado gran importancia en los últimos años como aporte a metodologías de conservación genética en tortugas marinas. El ADN$\mathrm{mt}$ consiste en una molécula circular de doble cadena la cual codifica para 22 tRNA, 2 rRNA y 13 proteínas además de una región mayor no codificable (región control, D-loop) (Drosopoulou et al., 2012). Una de las técnicas utilizadas para la obtención del genoma mitocondrial de tortugas marinas es la reacción en cadena de la polimerasa (PCR), con la que se demuestra la presencia de los fragmentos amplificados del ADN mitocondrial del organismo. La amplificación del genoma mitocondrial completo de las tortugas carey y cabezona permitirá realizar mejores análisis descriptivos, filogenéticos y evolutivos, además de aportar y mejorar la información sobre su estado genético ofreciendo aportes a estudios de planes de manejo y conservación de estas tortugas marinas en el Caribe colombiano. Por tal razón el propósito de este estudio fue estandarizar las mejores condiciones de la técnica de PCR para la amplificación del genoma mitocondrial de las tortugas cabezona y carey anidantes del Caribe colombiano, con el fin de vali- 
dar y mejorar protocolos establecidos para futuras investigaciones.

\section{Metodología}

\section{Obtención de muestras de sangre}

Se colectaron muestras de sangre periférica de las tortugas carey ( $E$. imbricata) y cabezona (C. caretta) en dos regiones del Caribe colombiano, el Oceanario Ceiner en la Isla de San Martín de Pajarales (Bolívar) y Playa Don Diego. Las muestras de sangre se obtuvieron a nivel de los senos dorsales cervicales, utilizando la metodología de Dutton (1996) y se almacenaron en tubos estériles con solución 0,1 M Tris-EDTA (GreinerBio-one ${ }^{\circ}$, Kremsmünster, Austria). Las muestras se transportaron en neveras con geles refrigerantes a $4{ }^{\circ} \mathrm{C}$ hasta el laboratorio de Biología Molecular de la Universidad Jorge Tadeo Lozano en Bogotá para su posterior análisis.

\section{Extracción de ADN}

El ADN se obtuvo utilizando el kit de extracción Handbook GF-1 vivantis Tissue DNA Extraction (MALA$S I A, H Q$ ) siguiendo el protocolo de la casa comercial fabricante (versión 2.2). Las extracciones se revelaron por electroforesis en gel de agarosa al $1 \% \mathrm{p} / \mathrm{v}$ en solución tampón TBE $0,5 X$ con tinción de bromuro de etidio $(2 \mu \mathrm{g} / \mathrm{ml})$ en una cámara horizontal GeIXL UltraV-2 (Labnet International, Inc. New Jersey, EE. UU.). El resultado de la separación se registró con el fotodocumentador UVP GelDoc-It ${ }^{\mathrm{TM}}$ System (UVP, Upland, EE. UU.) y se analizaron con el programa Vision Works ${ }^{\circ}$ LS ImageAcquisition and Analysis Software (Imagingsystem, EE. UU.). Los DNA fueron cuantificados en el nanodrop 1000 Spectrophotometter $y$ analizados con el programa ND-1000 V3.7.1.

\section{Diseño de oligonucleótidos-primers}

Se diseñaron 22 pares de oligonucleótidos-primers basados en la secuencia del genoma mitocondrial de la tortuga verde Chelonia mydas (Kumazaway $\mathrm{Ni}$ shida, 1999) para amplificar los 16.500 pb del mitogenoma de las dos tortugas en fragmentos de 800 $\mathrm{pb}$ solapados en $50 \mathrm{pb}$, para generar secuencias contiguas y facilitar el ensamblaje de la molécula (Figura 1).

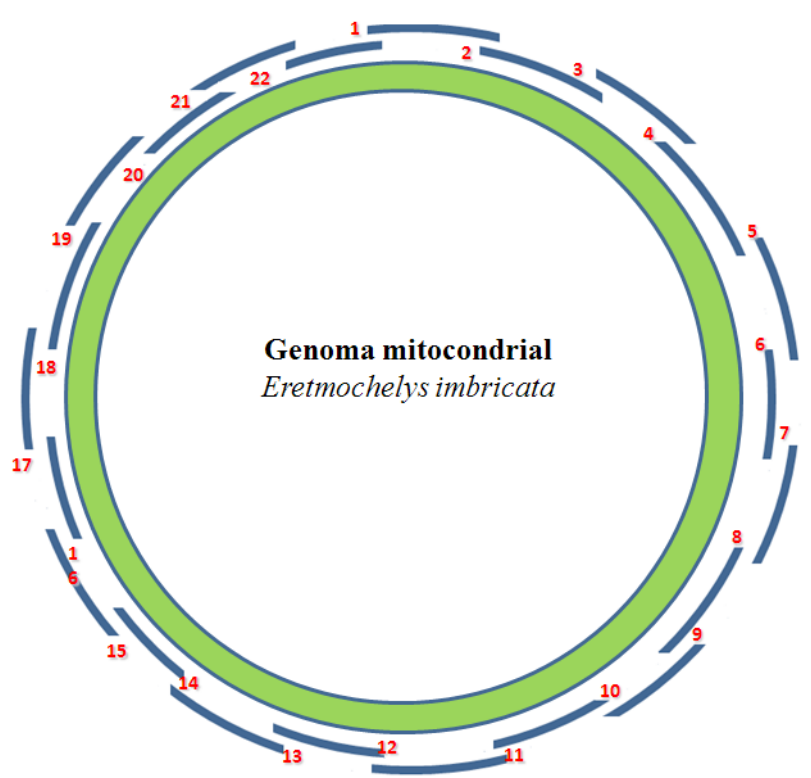

Figura 1. Estrategia de amplificación y ensamble de los 22 fragmentos de $800 \mathrm{pb}$ solapados en $50 \mathrm{pb}$.

\section{Estandarización de la PCR}

Se evaluó la concentración de $\mathrm{Mg}^{+2}$ entre 1-3 mM, la de DNA entre 10-100 ng, 0,5-2 oligonucleótidos-primers y la temperatura de anillamiento. Se identificó la temperatura teórica de cada uno de los oligonucleótidos-primers (IDT Olygo-analyzing) y a partir de esta se variaron para encontrar la temperatura óptima en la amplificación de una única banda de 800 pb.

Para determinar la calidad de los productos de la PCR, $2 \mu \mathrm{l}$ de cada amplificación se mezclaron con el mismo volumen $(2 \mu \mathrm{l}$ ) de buffer de carga (30 \% glicerol y $0,05 \%$ azul de bromofenol p/v), esta mezcla se sirvió en los pozos de un gel de agarosa preparado al $1 \%$ $(\mathrm{p} / \mathrm{v})$ en TBE $0,5 \mathrm{X}$ y teñido con bromuro de etidio ( 2 $\mu \mathrm{g} / \mathrm{ml})$. La amplificación de los fragmentos de ADNmt de $C$. caretta y E. imbricata se verificaron evidenciando en el gel la presencia de una única banda de 800 pares de bases (bp) utilizando el marcador de peso molecular Hiperladder IV (Bioline Inc., California, EE. UU.). El anterior proceso se registró con el fotodocumentador UVP Gel-Doc-IT ${ }^{\mathrm{TM}}$ System (UVP, Upland, 
EE. UU.) y se analizó con el programa VisionWorksLs (Imaging System, EE. UU.).

\section{Secuenciación}

Se obtuvo la secuencia nucleotídica en ambas direcciones $\left(5^{\prime}-3^{\prime}\right.$ y $\left.3^{\prime}-5^{\prime}\right)$ utilizando el método automatizado tagDyeDeoxy Terminator Cycle-sequencing en un secuenciador 3730XL (Applied Biosystems).

\section{Análisis de datos}

Las secuencias del ADNmt obtenidas por PCR de las tortugas $C$. caretta y $E$. imbricata se ensamblaron y alinearon utilizando el programa Geneious R6 (Auc- kland, Nueva Zelanda). La comparación de las secuencias obtenidas con las reportadas en la base de datos del NCBI se realizaron con la herramienta de búsqueda de alineamiento básico local, BLAST (http://blast. ncbi.nlm.nih.gov/) para determinar su identidad.

\section{Resultados}

Para amplificar el genoma mitocondrial de las tortugas $C$. caretta y E. Imbricata, se diseñaron manualmente 22 pares de oligonucleótidos-primers (Tabla 1) a partir de la secuencia del genoma mitocondrial de la tortuga verde Chelonia mydas (Kumazawa y $\mathrm{Ni}$ shida, 1999). Estos amplifican regiones de 800 pb que se solapan en $50 \mathrm{pb}$ con el fin de realizar el ensamble de estos fragmentos generando un solo conting (Figura 1).

Tabla 1. Oligonucleótidos-primers diseñados para amplificar el genoma mitocondrial de la tortuga cabezona (C. caretta) y carey $(E$. imbricata) con la región de amplificación dentro del genoma.

\begin{tabular}{|c|c|c|c|c|c|}
\hline $\begin{array}{c}\# \\
\text { Nombre }\end{array}$ & $\begin{array}{c}5^{\prime}-3^{\prime} \\
\text { oligonucleótido directo }\end{array}$ & $\begin{array}{c}\# \\
\text { nombre }\end{array}$ & $\begin{array}{l}\qquad 3^{\prime}-5^{\prime} \\
\text { oligonucleótido reverso }\end{array}$ & $\begin{array}{c}\text { pb } \\
\text { pares de bases }\end{array}$ & Gen \\
\hline CC1F & GTTATTGTAGCTTATTATAT & CC1R & TCTTCCATCTCAGTTAGCTA & $1-800$ & $12 \mathrm{~s}$ \\
\hline $\mathrm{CC} 2 \mathrm{~F}$ & CCTAAACAATTAATAAGTCA & $\mathrm{CC} 2 \mathrm{R}$ & TTAAGTACTTTATGTTGTTT & $750-1550$ & $12 s-16 s$ \\
\hline $\mathrm{CC} 3 \mathrm{~F}$ & TAGCTGGTTGCTCAATAAAA & CC3R & TCGCCCCAACCAAAAATATAG & $1500-2300$ & $16 \mathrm{~s}$ \\
\hline $\mathrm{CC} 4 \mathrm{~F}$ & TATAACTAACTAGTACTTGAC & CC4R & AAGGCTAATATTGGGGATAT & 2250- 3050 & 16s-ND1 \\
\hline CC5F & CСATCAАACTCATCCATTAC & CC5R & CAAGGTGATCCTTTGTTCAG & $3000-3800$ & ND1 \\
\hline $\mathrm{CC} 6 \mathrm{~F}$ & GGACTCCCACCTATACCATAG & CC6R & TTGTAATTATTCATCCTAGATGGG & $3750-4550$ & ND2 \\
\hline CC7F & TACGAAAAATCATAGCATTC & CC7R & ATTGCAAATTTAAAGATATATCT & $4500-5300$ & ND2 \\
\hline $\mathrm{CC} 8 \mathrm{~F}$ & TAAAAAGCGGGAAAACCCAG & CC8R & GTTGTATTTAGATTTCGGTCTGT & $5250-6050$ & $\mathrm{COI}$ \\
\hline $\mathrm{CC9F}$ & GTACTCGCCGCAGGCATTACCA & CC8R & ATAACTACTGCTACTATAGAGA & $6000-6800$ & $\mathrm{COI}$ \\
\hline $\mathrm{CC} 10 \mathrm{~F}$ & AАCTCTATTTCATCAATTGG & CC10R & TCAGCTGAGATTAGTATTC & $6750-7550$ & COI-COII \\
\hline $\mathrm{CC} 11 \mathrm{~F}$ & ATCGCATAGTAATACCAATA & CC11R & TCATATTGGAATAGCTAGTC & $7500-8300$ & COII-ATP8-ATP6 \\
\hline $\mathrm{CC} 12 \mathrm{~F}$ & СTACTAGGCCTTCTACCCTA & CC12R & TGGGGTAATTCCTGTAGGTG & $8250-9050$ & ATP6-COIII \\
\hline $\mathrm{CC} 13 \mathrm{~F}$ & CCCCTACCCCAGAACTAGGA & CC13R & AAGGTGAGAGTTGGGGATGG & $9000-9800$ & COIII-ND3-ND4L \\
\hline CC14F & СТССТАССССТАССАТGА & CC14R & GTAGTAGGATAATGGTGAAGATA & $9750-10550$ & ND4L-ND4 \\
\hline CC15F & CACTGAACCAACTTCACGAA & CC15R & TTAGTGGGAGTAAGAGTTGT & $10500-11300$ & ND4 \\
\hline $\mathrm{CC} 16 \mathrm{~F}$ & CCAACACAA ATTACGAACG & CC16R & GAATGTGGATGTAGTTGATC & $11250-12050$ & ND4-ND5 \\
\hline CC17F & TGAATCTATCATCACCAACT & CC17R & TAGTTGTGGTTGATTTAGGC & $12000-12800$ & ND5 \\
\hline $\mathrm{CC} 18 \mathrm{~F}$ & GCCAACTGGGCCTCATAATA & CC18R & СTCATCACAAAAAGGCCTAA & $12750-13550$ & ND5 \\
\hline CC19F & TGAAAATATTGGTCCAAAAGGA & CC19R & CTTGGTAGGTCGATGACTA & $13500-14300$ & ND5-ND6 \\
\hline CC2OF & CCCACCCAATAATAAAAATT & CC2OR & GTATCATTCTGGTTTGATGT & $14250-15050$ & Citocromo B \\
\hline CC21F & CACCAGCCAACCCTCTATCC & CC21R & CAATTACTGTGACGATATTCA & $15000-15800$ & Citocromo B \\
\hline $\mathrm{CC} 22 \mathrm{~F}$ & TAAAATTAAACTATTATACT & CC22R & ATATTATATATATAATATATATA & $15750-16497$ & D-loop-12s \\
\hline
\end{tabular}


La Figura 2 muestra la extracción de ADN total realizada a un individuo de la tortuga carey y a otro de la tortuga cabezona respectivamente, en esta se puede ver la calidad y apariencia de las extracciones, sin rastros de contaminantes ni residuos de ARN que puedan modificar las reacciones de PCR.

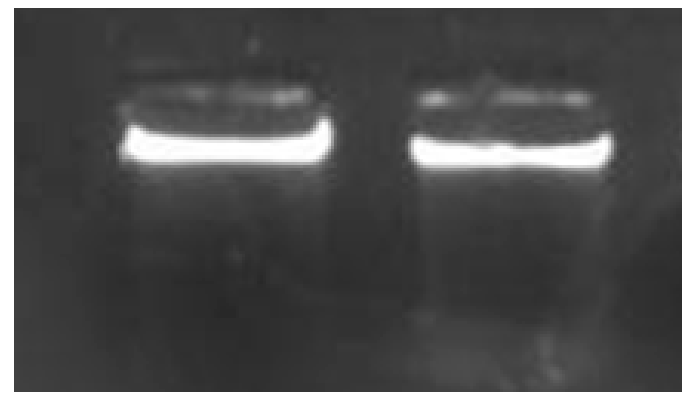

Figura 2. ADN total de las dos tortugas marinas Carril 1: tortuga carey. Carril 2: tortuga cabezona. Electroforesis en gel de agarosa al $1 \%$ teñida con bromuro de etidio

La estandarización del cloruro de magnesio $\left(\mathrm{MgCl}_{2}\right)$ en la mezcla de reacción se varió entre 1 y $3 \mathrm{mM}$. La Figura 3 muestra el efecto en las variaciones de este componente para los fragmentos 2 (carril 1 y 2) y 16 (carril 3 y 4 ) de la tortuga carey, se pudo observar que en concentraciones menores de $\mathrm{MgCl}_{2}$ no se presentan las bandas deseadas, mientras que mayores concentraciones inducen la amplificación de un buen número de bandas, dentro de las cuales se encuentra la banda de interés de $800 \mathrm{pb}$. Como se observa en la Figura 3, una concentración de 1,5 mM amplifica el fragmento 2, mientras la concentración $2 \mathrm{mM}$ de $\mathrm{MgCl}_{2}$ mejora la amplificación del fragmento 16 .

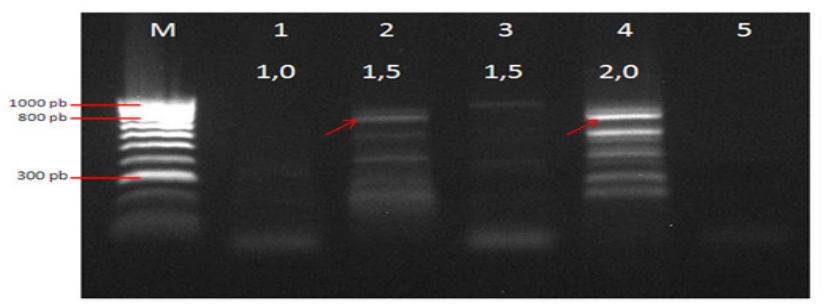

Figura 3. Estandarización de $\mathrm{MgCl}_{2}(\mathrm{mM})$ de los fragmentos 2 y 16 de la tortuga carey. Carril 1 y 2: fragmento 2, Carril 3 y 4: fragmento 16, Carril 5: Control negativo. M: Marcador de peso HyperLadder IV. Electroforesis en gel de agarosa teñido con bromuro de etidio. Las flechas señalan las bandas de interés.
De la misma forma se realizó el procedimiento para la estandarización de la concentración de los oligonucleótidos-primers. La Figura 4 muestra variaciones en la concentración, de entre 0,5 y 1 uM en la amplificación de dos fragmentos diferentes de la tortuga carey, se observa cómo para el fragmento 4 (carriles 1 , 2 y 3) la concentración de $1 \mu \mathrm{M}$ amplifica una banda de 800 pb más intensa y nítida, mientras que para el fragmento 12 (carriles 5, 6 y 7), la banda esperada de 800 pb se obtiene con $0,8 \mu \mathrm{M}$ de oligonucleótidos-primers. De esta misma manera se evaluaron las demás 20 parejas de oligonucleótidos-primers (Tabla 2).

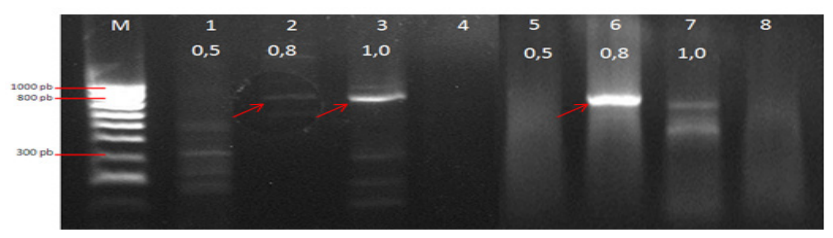

Figura 4. Evaluación de la concentración de oligonucleótido-primer 4 y 12 del mitogenoma de la tortuga carey. Carril 1, 2 y 3: oligonucleótido-primer 4. Carril 5, 6 y 7: oligonucleótido-primer 12. Carril 4 y 8: Controles negativos. M: Marcador de peso HyperLadder IV. Debajo de los números de los carriles se muestran las concentraciones de oligonucleótidos-primers en concentración $\mathrm{mM}$. Electroforesis de agarosa al $1 \%$ teñida con bromuro de etidio. Las flechas señalan las bandas de interés.

Para estandarizar la temperatura de melting o anillamiento $(\mathrm{Tm})$ se calculó la temperatura teórica y se realizaron reacciones con temperaturas $5{ }^{\circ} \mathrm{C}$ por debajo (BIOTOOLS,2009). En la Figura 5 A se observan reacciones de PCR donde se evalúan diferentes temperaturas para 3 fragmentos (fragmento 7 , en los carriles 1, 4 y 7; fragmento 10 en los carriles 2,5 y 8 y fragmento 11 en los carriles 3,6 y 9) para el mitogenoma de la tortuga carey. La primera amplificación se realizó a $35^{\circ} \mathrm{C}$ (carriles 1,2 y 3 ), la siguiente a $36{ }^{\circ} \mathrm{C}$ (carriles 4,5 y 6) y la última a $37^{\circ} \mathrm{C}$ (carriles 7,8 y 9). Se observa que en la medida en que la temperatura aumenta $1{ }^{\circ} \mathrm{C}$ las bandas inespecíficas desaparecen, generando mayor especificidad en la amplificación del fragmento esperado. En la Figura 5B se observa la amplificación del fragmento 5 de la tortuga cabezona, una primera amplificación a $43{ }^{\circ} \mathrm{C}$ (carril 1 ) y posteriormente a 45 ${ }^{\circ} \mathrm{C}$ (carril 2), el aumento en $2{ }^{\circ} \mathrm{C}$ genera la aparición de la banda esperada. La Figura $5 \mathrm{C}$ presenta la amplificación de los fragmentos 3, 15 y 16 (fragmento 3, en los 
carriles 1 y 4 ; fragmento 15 , en los carriles 2 y 5 y fragmento 16 , en los carriles 3 y 6 ) de la tortuga cabezona, la primera amplificación se realizó a $40^{\circ} \mathrm{C}$ (carriles 1,2 y 3) y la segunda a $45^{\circ} \mathrm{C}$ (carriles 4,5 y 6 , aumentando la $\mathrm{Tm}$ en $5^{\circ} \mathrm{C}$ para obtener una mayor especificidad en las bandas esperadas).

Tabla 2.Condiciones estandarizadas de la reacción de PCR para cada uno de los 22 fragmentos que amplifican el genoma mitocondrial de las tortugas cabezona (Caretta caretta) y carey (Eretmochelys imbricata).

\begin{tabular}{|c|c|c|c|c|c|c|c|c|c|c|}
\hline \multirow{2}{*}{$\begin{array}{l}\text { Organismo } \\
\text { Fragmento }\end{array}$} & \multicolumn{5}{|c|}{ Caretta caretta } & \multicolumn{5}{|c|}{ Eretmochelys imbricata } \\
\hline & $\begin{array}{c}\text { elt } \\
\text { Teórica } \\
\left({ }^{\circ} \mathrm{C}\right)\end{array}$ & $\begin{array}{c}\mathrm{Tm} \\
\text { Práctica } \\
\left({ }^{\circ} \mathrm{C}\right)\end{array}$ & $\begin{array}{l}\text { Primer } \\
(\mu \mathrm{M})\end{array}$ & $\begin{array}{c}\text { ADN } \\
(\mathrm{ng} / \mu \mathrm{l})\end{array}$ & $\begin{array}{l}\mathrm{MgCl}_{2} \\
\text { (mM) }\end{array}$ & $\begin{array}{l}\text { Tm Teó- } \\
\text { rica }\left({ }^{\circ} \mathrm{C}\right)\end{array}$ & $\begin{array}{c}\text { Tm Práctica } \\
\left({ }^{\circ} \mathrm{C}\right)\end{array}$ & $\begin{array}{l}\text { Primer } \\
(\mu \mathrm{M})\end{array}$ & $\begin{array}{c}\text { ADN (ng/ } \\
\mu l)\end{array}$ & $\begin{array}{l}\mathrm{MgCl}_{2} \\
\text { (mM) }\end{array}$ \\
\hline 1 & 48.8 & 33 & - & 60 & - & 48,8 & 33 & 1 & 60 & 2.5 \\
\hline 2 & 42 & 35 & 1 & 60 & 2 & 42,2 & 35 & 1 & 60 & 1,5 \\
\hline 3 & 51 & 47 & 0.5 & 50 & 2 & 51,0 & 46 & 0,8 & 50 & 1,5 \\
\hline 4 & 45.7 & 40 & 0.8 & 60 & 2 & 45,7 & 42 & 1 & 60 & 1,5 \\
\hline 5 & 49.85 & 45 & 0.8 & 70 & 2.5 & 49,9 & 44 & 0,8 & 70 & 1,5 \\
\hline 6 & 51.03 & 45 & 1 & 30 & 2 & 51,3 & 45 & 0,8 & 30 & 1,5 \\
\hline 7 & 44.9 & 37 & 1 & 60 & 2 & 45,0 & 37 & 1 & 60 & 1,5 \\
\hline 8 & 52.15 & 46 & 1 & 30 & 2 & 52,2 & 46 & 0,8 & 30 & 1,5 \\
\hline 9 & 46.2 & 45 & 1 & 30 & 2 & 46,3 & 45 & 0,8 & 30 & 1,5 \\
\hline 10 & 45.5 & 37 & 1 & 50 & 1.5 & 45,5 & 37 & 1 & 50 & 1,5 \\
\hline 11 & 45.8 & 37 & 1 & 60 & 2 & 45,8 & 37 & 1 & 60 & 1,5 \\
\hline 12 & 52.8 & 44 & 0.8 & 40 & 2 & 52,9 & 45 & 0,8 & 40 & 1,5 \\
\hline 13 & 57.6 & 50 & 1 & 50 & 2 & 57,2 & 50 & 1 & 50 & 1,5 \\
\hline 14 & 50.55 & 47 & 0.8 & 60 & 2.5 & 50,6 & 45 & 0,8 & 60 & 2.5 \\
\hline 15 & 51.5 & 45 & 1 & 30 & 2 & 51,6 & 46 & 0,8 & 30 & 1,5 \\
\hline 16 & 48.9 & 44 & 0.8 & 50 & 2 & 48,9 & 43 & 1 & 50 & 2 \\
\hline 17 & 49.1 & 43 & 0.8 & 70 & 2 & 49,2 & 43 & 1 & 70 & 2,5 \\
\hline 18 & 52.3 & 42 & 0.8 & 70 & 2 & 52,6 & 43 & 1 & 70 & 2 \\
\hline 19 & 50.4 & 42 & 0.8 & 60 & 2 & 50,4 & 46 & 0.8 & 60 & 2,5 \\
\hline 20 & 46.7 & 35 & 0.8 & 60 & 1.5 & 46,8 & 38 & 1 & 60 & 2,5 \\
\hline 21 & 49.3 & 40 & 1 & 40 & 1.5 & 49,4 & 43 & 1 & 40 & 1,5 \\
\hline 22 & 32.7 & - & - & - & - & 32,7 & 28 & 2 & 50 & 3 \\
\hline
\end{tabular}



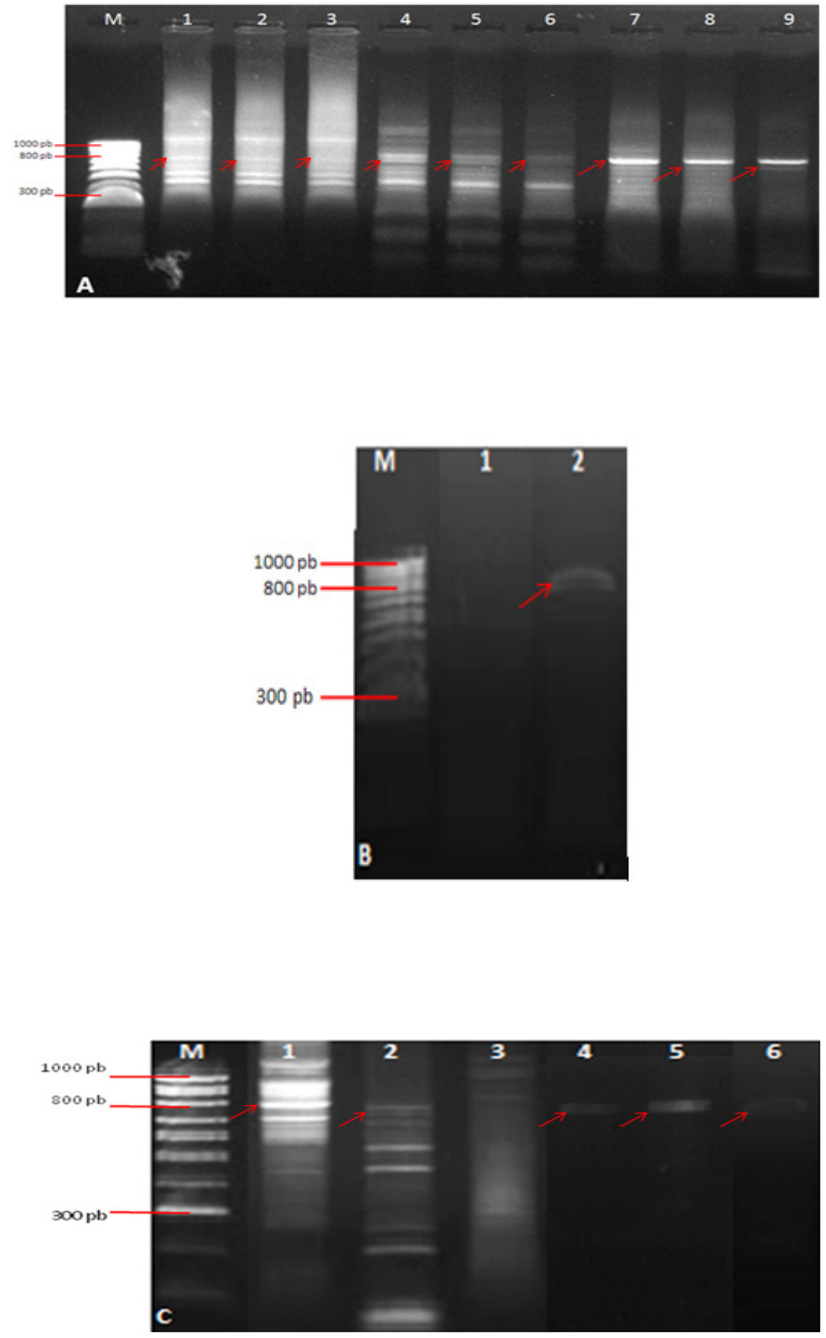

Figura 5. Evaluación de la temperatura de melting $(\mathrm{Tm})$ o anillamiento sobre diferentes fragmentos del DNAmt de las tortugas carey y cabezona. 5A) Tm de los fragmentos 7, 10 y 11 del DNAmt de la tortuga carey. Carril 1, 2 y 3: $\mathrm{Tm} 35^{\circ} \mathrm{C}$. Carril 4, 5 y 6: $\mathrm{Tm} 36^{\circ} \mathrm{C}$. Carril 7, 8 y 9: $\mathrm{Tm} 37^{\circ} \mathrm{C}$. 5B) Tm del fragmento 5 del DNAmt de la tortuga cabezona. Carril 1: Tm $43{ }^{\circ} \mathrm{C}$. Carril 2: $\mathrm{Tm} 45^{\circ} \mathrm{C}$. 5C) Tm de los fragmentos 3,15 y 16 del DNAmt de la tortuga cabezona. Carril 1,2 y $3: \operatorname{Tm} 40^{\circ} \mathrm{C}$. Carril 4, 5 y 6: $\mathrm{Tm} 45^{\circ} \mathrm{C}$. M: Marcador de peso HyperLadder IV. Electroforesis en gel de agarosa teñido con bromuro de etidio. Las flechas señalan las bandas de interés.

La Figura 6 presenta la amplificación por PCR de nueve fragmentos (fragmentos 3, 6, 7, 8, 9, 10, 11, 13, 18) de DNAmt de la tortuga carey después de haber realizado la estandarización para cada una de las variables evaluadas, se observan bandas únicas de 800 pb. La variación en la intensidad y ancho de cada una de las bandas sugiere la concentración del ADN (ng/ $\mu \mathrm{l})$ que fue cuantificada en nanodrop. En la Figura 6 se observan ban- das con concentraciones que oscilaron entre 40-60 ng/ $\mu l$ (Tabla 3). Los productos obtenidos fueron almacenados a $-20^{\circ} \mathrm{C}$ para enviar posteriormente a secuenciar.

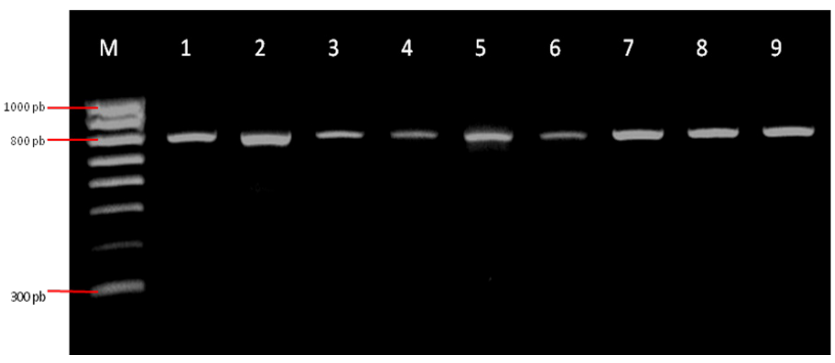

Figura 6. Amplificación por PCR de 9 fragmentos amplificados de la tortuga carey, mostrando un peso de $800 \mathrm{pb}$. Marcador de peso molecular HyperLader IV (100-1000 pb). Electroforesis en gel de agarosa al $1 \%$ teñida con bromuro de etidio.

Tabla 3. Cuantificación por nanodrop de 9 fragmentos de ADN amplificados para el mitogenoma de la tortuga carey.

\begin{tabular}{ccc}
\hline Carril & Fragmento & $\begin{array}{c}\text { Concentración de ADN } \\
\text { (ng/ } \mu \text { l) }\end{array}$ \\
\hline 1 & 3 & 50,5 \\
2 & 6 & 60,0 \\
3 & 7 & 49,7 \\
4 & 8 & 40,0 \\
5 & 9 & 50,1 \\
6 & 10 & 40,3 \\
7 & 11 & 59,8 \\
8 & 13 & 59,2 \\
9 & 18 & 58,9 \\
\hline
\end{tabular}

La mezcla de reacción estandarizada se realizó en volumen final de $25 \mu \mathrm{l}$, que incluyó 20-50 ng de DNA, 0,5-1 mM de cada primer, 1,5-3 mM de $\mathrm{MgCl}_{2}, 1 \mathrm{U}$ de Taq polimerasa y $0,2 \mathrm{mM}$ de cada dNTP's, condiciones específicas para cada uno de los fragmentos de los mitogenomas de las tortugas analizadas (Tabla 2). El programa del termociclador se inició con una desnaturalización por $5 \min$ a $94^{\circ} \mathrm{C}$, seguida por $25-35$ ciclos (dependiendo del fragmento) de $94{ }^{\circ} \mathrm{C}$ por $1 \mathrm{~min}$, 30-50 ${ }^{\circ} \mathrm{C}$ por $1 \mathrm{~min}$ (de acuerdo al oligonucleótido-pri- 
mer) y $72{ }^{\circ} \mathrm{C}$ por $1 \mathrm{~min}$, con una extensión final de 10 $\min$ a $72{ }^{\circ} \mathrm{C}$.

Los fragmentos amplificados de la tortuga cabezona y carey se enviaron a secuenciar a la empresa Macrogen (Korea), utilizando la metodología de Sanger. Las secuencias obtenidas se sometieron a un análisis preliminar de BLAST para corroborar la identidad con las secuencias previamente reportadas, posteriormente se ensamblaron utilizando el programa Geneious R6, generándose los contings. Se obtuvo el $63 \%$ de la secuencia de la tortuga carey y el $68 \%$ de la tortuga cabezona. Estas secuencias presentaron un $99-100 \%$ de identidad con las secuencias previamente descritas y dentro de estas se pudieron identificar 6 genes completos y 13 tRNA para la tortuga carey y 6 genes completos y 14 tRNA para la tortuga cabezona (Tabla 4).

Tabla 4. Genes identificados en el mitogenoma secuenciado de las tortugas cabezona y carey.

\section{Caretta caretta Eretmochelys imbricata}

\begin{tabular}{cc}
\hline COI & COI \\
ND2 & ND2 \\
COII & COII \\
COIII & COIII \\
ATP6 & ATP6 \\
ATP8 & ATP8 \\
14 tRNAs & 13 tRNAs \\
\hline
\end{tabular}

\section{Discusión}

Las variaciones realizadas a la concentración del cloruro de magnesio, oligonucleótidos-primers y Tm permitieron la optimización en la amplificación por PCR de 22 fragmentos del ADNmt de las dos tortugas (carey y cabezona), nueve fragmentos amplificados se observan en la Figura 6, donde se evidencia una única banda de 800 pb. Se obtuvo entre el $60-70 \%$ de la secuencia nucleótidica del mitogenoma de las dos tortugas. La estandarización de un protocolo de PCR es un proceso que genera un alto costo en tiempo y reactivos, especialmente dado por las propias reacciones que pueden llegar a ser impredecibles y variables. Los pequeños cambios realizados en alguno de los reactivos o temperaturas usadas van a afectar directamente el resultado de la amplificación del genoma, de este manejo en las variables y sus modificaciones va a depender la calidad y pureza de la amplificación final, ya sea cambiando las concentraciones de los reactivos (cloruro de magnesio, dNTP's, primers, DNA) así como las temperaturas y tiempos en el termociclador (Roux, 2002).

Uno de las variables principales a considerar para una óptima amplificación es la temperatura de anillamiento; la unión o rehibridación de las hebras de ADN se efectúa a una temperatura generalmente de entre 55 y $65{ }^{\circ} \mathrm{C}$ (Cortázar \& Rincón, 2004). Sin embargo, la temperatura máxima de amplificación del genoma mitocondrial de las tortugas cabezona ( $C$. caretta) y carey (E. imbricata) fue de $50{ }^{\circ} \mathrm{C}$ para el oligonucleótido-primer 13 , mientras que la temperatura más baja fue de $28{ }^{\circ} \mathrm{C}$ para el 22 (Tabla 1 y 2). Con estas temperaturas se logró el anillamiento y producir la unión del ADN molde con el cebador para la óptima amplificación, difiriendo considerablemente entre las temperaturas ya descritas (Cortázar \& Rincón, 2004). Se corrobora que temperaturas de hibridación muy elevadas pueden ocasionar que el cebador no se una correctamente con la región homologa, y por ende, no se produzca amplificación (Quiñones, 2011), razón por la cual a que ninguno de los fragmentos de los mitogenomas amplificaron a temperaturas mayores a los $50^{\circ} \mathrm{C}$.

Para una excelente estandarización es de considerar la especificidad de los oligonucleótidos-primers que es en parte dependiente de su longitud (Pinzón, 2006). Los oligonucleotidos-primers deben ser elegidos de modo que tengan una secuencia única dentro del DNA que será amplificado. Un primer diseñado con una secuencia altamente repetida dará lugar a productos no deseados (Cortázar \& Rincón, 2004), siendo el caso de los oligonucleótidos-primers 3, 7, $10,11,15$ y 16 (Figuras $5 \mathrm{~A}$ y $5 \mathrm{C}$ ) que amplifican más de una banda mostrando una baja especificidad. Para el caso de oligonucleótidos-primers de la Figura 5B se evidencia una alta especificidad que se presenta principalmente por el contenido de GC (Pinzón, 2006) y el contenido de $\mathrm{MgCl}_{2}$ utilizado en la reacción. 
Una buena especificidad en las bandas deseadas de los productos de PCR también depende en gran medida de la Tm para que los primers se unan a los sitios exactos dentro de la cadena molde. La Tm usada para la amplificación de un fragmento se basa en el promedio generado por las temperaturas de los primers implicados en la reacción, por lo general se utiliza una Tm menor a la obtenida en el consenso y en base a este se inicia el proceso de estandarización para encontrar el punto que genere una mayor especificidad (Kolmodin y Birch, 2002), como se puede observar en las Figuras 3 y 6 , el aumento de la Tm para la amplificación de los diferentes fragmentos fue generando una mayor especificidad en la obtención de las bandas de 800 pb. Se ha mencionado que la máxima diferencia de temperatura para la amplificación experiemental es de $5{ }^{\circ} \mathrm{C}$ en relación a la temperatura teórica (Avila et al., 1993, BIOTOOLS, 2009), para el caso del genoma mitocondrial la temperatura de anillamiento teórica respecto a la experimental varía considerablemente en algunos casos, siendo el intervalo de diferencia más alto de $10{ }^{\circ} \mathrm{C}$, sugiriendo que estos patrones observados de altas diferencias de rangos de temperaturas son dependientes de la longitud de los primers (Pinzón, 2006).

La concentración de cloruro de magnesio es un factor importante en la mezcla de reacción para la PCR. Los iones magnesio sirven como cofactores de la enzima Taq polimerasa, la cual impulsa a los primers para iniciar la replicación de la cadena molde (Kolmodin y Birch, 2002). Según lo reportado por Llauger et al. (2003), concentraciones bajas de $\mathrm{MgCl}_{2}(1,5 \mathrm{mM})$, tienen una intensidad del producto amplificado muy débil y los resultados no son reproducibles, mientras que concentraciones altas $(2,5 \mathrm{mM})$ teniendo en cuenta la homogeneidad de los resultados con respecto al tamaño de la banda, nitidez, intensidad y reproducibilidad son ideales, coincidiendo con los resultados de optimización para la concentración de cloruro de magnesio descritas en este estudio.

Pinzón (2006) reporta un indicador importante para la optimización de resultados de PCR, mencionando que la temperatura de fusión de los primers depende principalmente del contenido de $\mathrm{G}+\mathrm{C}$, permitiendo estabilizar la molécula por la presencia de los 3 enlaces de hidrogeno que presentan este par de bases nitrogenadas. El contenido en $\mathrm{G}+\mathrm{C}$ del primer debe ser entre 40 y $60 \%$ siendo óptimo el $50 \%$. Los primers con un menor contenido en GC deben diseñarse algo más largos para conseguir una $T m$ por encima de la recomendada (Cortázar \& Rincón, 2004). Los contenidos de G+C de los primers 1 y 22 corresponden al $30 \%$ y $15 \%$ respectivamente (OligoAnalyzer 3.1- IDT), con las temperaturas de anillamiento practicas más bajas de los dos genomas, evidenciándose poca especificidad y problemas en la amplificación de los fragmentos de interés. Por tal razón se sugiere la modificación del tamaño de los primers 1 y 22, para una óptima amplificación.

Estos resultados hicieron posible la estandarización de una metodología de gran utilidad para la obtención de la secuencia del genoma mitocondrial de tortugas marinas del Caribe colombiano, generando aportes significativos en el proceso de conocimiento genético de estas especies. Las secuencias obtenidas serán analizadas bioinformáticamente.

\section{Conclusiones}

Se confirma en este estudio que las concentraciones de $\mathrm{MgCl}$, primers-oligonucleotidos y la variación en temperatura de anillamiento permiten una mayor especificidad de la amplificación de bandas de interés. Para la reacción estandarizada de PCR de los genomas mitocondriales de las tortugas carey y cabezona, la temperatura de anillamiento no superó los $50{ }^{\circ} \mathrm{C}$, la concentración de cada oligonucleótido-primer y $\mathrm{Mg}^{+2}$ osciló entre los 0,5-1 mM y 1,5-3,0 mM, confirmando temperaturas y concentraciones previamente descritas. La concentración de Taq polimerasa y dNTP's se mantuvo constante $1 \mathrm{U}$ y $0,2 \mathrm{mM}$ respectivamente. La finalización de la secuenciación de los genomas mitocondriales de estas tortugas permitirá realizar diversos análisis (filogeneticos, evolutivos y filogeográficos, entre otros) que apoyen proyectos de conservación de estas tortugas en el Caribe colombiano.

\section{Agradecimientos}

Los autores agradecen al Oceanario Ceiner y a la profesora Aminta Jáuregui por la ayuda en la consecución de las muestras de sangre de las dos tortugas marinas. A la Dirección de Investigación, Creatividad e Innovación de la Universidad Jorge Tadeo Lozano por el apoyo a este estudio. Las muestras fueron obtenidas bajo permiso de investigación concedido por el Ministerio de Medio Ambiente y Desarrollo Territorial ( $\mathrm{N}^{\circ} 24$, del 22 de junio de 2012) y el Contrato de Acceso a los Recursos Genéticos ( $N^{\circ}$ 64, del 23 de abril de 2013). 


\section{Referencias}

Amorocho, D. F., \& Network, W. C. S. T. C. (1999, November). Status and distribution of the hawksbill turtle, Eretmochelys imbricata, in the wider Caribbean region. In Proceedings of the Regional Meeting "Marine Turtle Conservation in the Wider Caribbean Region: A Dialogue for Effective Regional Management", Santo Domingo (pp. 16-18).

Avila, J. T., De Vera, A. M., Calzadilla, C. H., \& Martin Vasallo, P. (1993). Análisis del DNA. II: Clonar, secuencíar y PCR. Nefrología, 13, 267-267.

BIOTOOLS, Biotechnological \& Medical Laboratories, S.A. (C) (2009). Biotools dna polymerase gel form. Consultado: 10-X-2013. Disponible en: http:// www.biotools.eu/esp/pdf/Boletines\%20de\%20 Producto/Enzimas/Enzimas\%20Tiempo\%20Final/ DNA_Polimerasa_Gel.esp.ed14.jul11.pdf

Cortázar, A., \& Rincón, E. (2004). Métodos Físico-Químicos en Biotecnología PCR. Universidad Nacional Autónoma de México Instituto de Biotecnología. (pp, 43).

Drosopoulou, E., Tsiamis, G., Mavropoulou, M., Vittas, S., Katselidis, K. A., Schofield, G., \& Scouras, Z. G. (2012). The complete mitochondrial genome of the loggerhead turtle Caretta caretta (Testudines: Cheloniidae): Genome description and phylogenetic considerations. Mitochondrial DNA, 23(1), 1-12.

Dutton, P. (1996). Methods for collection and preservation of simple for sea turtle genetic studies, $p$. 17-24. En: B. W. Bowen y W. N. Witzell (Editores), Proceedings of the International Symposium on Sea Turtles Conservation Genetics, NOAA Techincal memorandum NMFS-SEFSC-396.173.

Eckert, K. L., Bjorndal, K. A., Abreu-Grobois, F. A., \& Donnelly, M. (2000). Técnicas de Investigación y Manejo para la Conservación de las Tortugas Marinas. Grupo Especialista en Tortugas Marinas. UICN/ CSE.(Traducción al español). Publicación, (4), 270.

Kolmodin, L. A., \& Birch, D. E. (2002). Polymerase Chain Reaction: Basic Principles and Routine Practice. EN: Chen, B-Y. y Janes, H. W. 2002. PCR Cloning Protocols. Methods in Molecular Biology. $2^{\text {nd }}$ Edition. 192. Humana Press Inc. Totowa, NJ.
Kumazawa, Y., \& Nishida, M. (1999). Complete mitochondrial DNA sequences of the green turtle and blue-tailed mole skink: statistical evidence for archosaurian affinity of turtles. Molecular Biology and Evolution, 16(6), 784-792.

Liu, Z. J., \& Cordes, J. F. (2004). DNA marker technologies and their applications in aquaculture genetics. Aquaculture, 238(1), 1-37.

Llauger, R., Peralta, E. L., Dollet, M., Cueto, J., Rodríguez, M., Fajardo, D., \& González, V. Diversidad y optimización del diagnóstico del fitoplasma asociado al amarillamiento letal del cocotero en Cuba. Documento FAO 2254

Machado, A., \& Bermejo J. A. (2012). Estado de Conservación de la Tortuga Boba (Caretta caretta) en las Islas Canarias. Plan de Seguimiento de la Tortuga Boba en Canarias. Santa Cruz de Tenerife: $O b$ servatorio Ambiental Granadilla, (pp, 154).

Márquez, R. (1990). Las tortugas marinas y nuestro tiempo. Fondo de Cultura Económica, Secretaría de Educación Pública. Consejo Nacional de Ciencia y Tecnología. México.

Meylan, A. B., \& Donnelly, M. (1999). Status justification for listing the hawksbill turtle (Eretmochelys imbricata) as critically endangered on the 1996 IUCN Red List of Threatened Animals. Chelonian Conservation and Biology, 3(2), 200-224.

Pinzón V, A. (2006). Introducción al diseño "in silico" de primers. Centro de Bioinformática del Instituto de Biotecnología en la Universidad Nacional de Colombia. Laboratorio de Micología y Fitopatología Universidad de los Andes, Colombia, (pp, 9).

Quiñonez Sánchez, A. M. (2012). Estandarización de las condiciones de PCR para la amplificación de citocromo oxidasa C, subunidad I (COI) y evaluación de su contenido informativo en dos poblaciones de Urotrygon aspidura del Pacífico vallecaucano [recurso electrónico] (Doctoral dissertation).

Roux, K. H. (2002). Single-step PCR optimization using touchdown and stepdown PCR programming. In PCR Cloning Protocols (pp. 31-36). Humana Press. 